\title{
The concentration of digoxin after intravenous and oral administration studied by a two-compartment model
}

\author{
V. Siva Rama Krishna Reddy ${ }^{a}$ and K. Lakshmi Narayan ${ }^{b}$ \\ ${ }^{a}$ Gokaraju Rangaraju Institute of Engineering and Technology, Hyderabad, India; ${ }^{b}$ Vidya Jyothi Institute of \\ Technology, Hyderabad, India
}

\begin{abstract}
The present paper is designed to compare the distribution of digoxin administered through an Intravenous (i.v.) and Oral (p.o.) in central and peripheral compartments. The model under consideration is denoted by a system of three non-linear ordinary differential equations. The Eigenvalue and the Laplace transform methods were used to solve the system of equations. In this model, digoxin was administered to three subjects through i.v. and three subjects through p.o. then, the serum concentrations were measured over a period of $6 \mathrm{~h}$. The transfer coefficients were obtained from digoxin concentrations using the method of residuals and the variation of digoxin concentration-time curves plotted using MATLAB. In this model, we consider excretion is only from the peripheral compartment.
\end{abstract}

\section{ARTICLE HISTORY}

Received 4 October 2018 Accepted 17 June 2019

\section{KEYWORDS}

Compartment model; eigenvalue; laplace transform; residual; digoxin; oral; intravenous; normal subjects

\section{Introduction}

Explanation of the simplest pharmacokinetic model in accordance with data observed for human drug adaptation is a necessary step for a full understanding of distribution, elimination, activity and drug toxicity. This is becoming increasingly important with drugs that have a low therapeutic index and serious side effects such as the cardiac glycoside digoxin. In view of its narrow therapeutic window, it is important to study the drug concentration in men at various times after oral (p.o.) and intravenous (i.v.) administration. Doherty, Flanigan, and Dalrymple (1972) distinguish the pharmacokinetics of digoxin after oral administration in seven normal patients of tritium-labelled digoxin. The mean half-life from digoxin concentration was $32.7 \mathrm{~h}$., while urinary elimination rates capitulated the mean half-life of $35.6 \mathrm{~h}$., approximately similar values of creatinine and digoxin renal clearances were identified. Gitfrich, Bodem, and Chidsey (1974) inspect the urinary excretion of tritiated digoxin after administering intravenously and reported an average half-life value of $50.8 \mathrm{~h}$. in six chronic disease patients with normal renal function. They found that the renal clearance of digoxin slightly exceeded the creatinine clearances. The steady-state volume of distribution of digoxin in normal subjects has been calculated by Reuning, Sams, and Notari (1973) from digoxin concentration data reported in three 
studies. J.J Vallner, Stewart, Kotzan, Kirsten, and Honigberg (1981) examined the elimination half-life of hydromorphone in six subjects was $2.64 \pm 0.88 \mathrm{~h}$ and the drug distributed in a high volume of $1.22 \mathrm{l} / \mathrm{kg}$. Also, the drug was very quickly but partially absorbed after oral administration.

Kannan, Singh, and Przekwas (2018) has shown using his Q3D-compartment multiscale models, the effect of the solubility on the regional presence of the ICS and its absorption across the different lung tissues to the vein/artery. In particular, it was found that highly soluble drugs like Budesonide (solubility coefficient $\sim 45 \mu \mathrm{g} / \mathrm{ml}$ ) dissolves very fast, then diffuses and then is cleared to the GUT region. On the other hand, poorly soluble drugs like FP (solubility coefficient $\sim 0.5-1.5 \mu \mathrm{g} / \mathrm{ml}$ ) being nearly insoluble, are present in chunks even after $1-2 \mathrm{~h}$ after the inhalation, and thus there is hardly any diffusion along the lung axis. Consequently, we see a secondary spike in the vein concentration at around $1.25 \mathrm{~h}$ time-frame, when the FP chunk (and the dissolved FP molecular drug, sticking to it) entering the GUT and to the vein. Similarly, the deposition of the ICS drug on the airway walls is equally important. For instance, Kannan et al. (2017), (Kannan, Guo, \& Przekwas, 2016) provides the factors affecting the deposition on the airways: (i) drug density, (ii) the inhaler geometry, (iii) the inhaled flow rate, (iv) the vorticity in the airways (causes increased deposition for smaller particles), (v) the cartilaginous ridges in the trachea and the generation-1 airways (causes increased deposition for smaller particles) and (vi) the enhanced deposition at the airway bifurcations, thereby restricting the drug to reach the lower airways and the alveoli. In cases like the FP/Budesonide drug, a significant portion of the inhaled corticosteroids (ICS) (from the dry powder inhalers) go and deposit on the alveoli (due to the factors mentioned earlier). All of the above contribute to the efficacy of the inhaled drug and the clearance effects (almost none in the alveoli).

In this present study, we formulated two-compartmental model as shown in Figure 1 which is denoted by a system of three non-linear ordinary differential equations (ODEs). The Eigenvalue and the Laplace transform methods were used to solve the system of equations. In this model, digoxin was administered to three subjects through i.v. and three subjects through p.o. then, the serum concentrations were measured respectively over a period of $6 \mathrm{~h}$. The transfer coefficients were obtained from digoxin concentrations using the method of residuals and the variation of digoxin concentration-time curves plotted using MATLAB In detail, we compare the distribution of digoxin in men administered

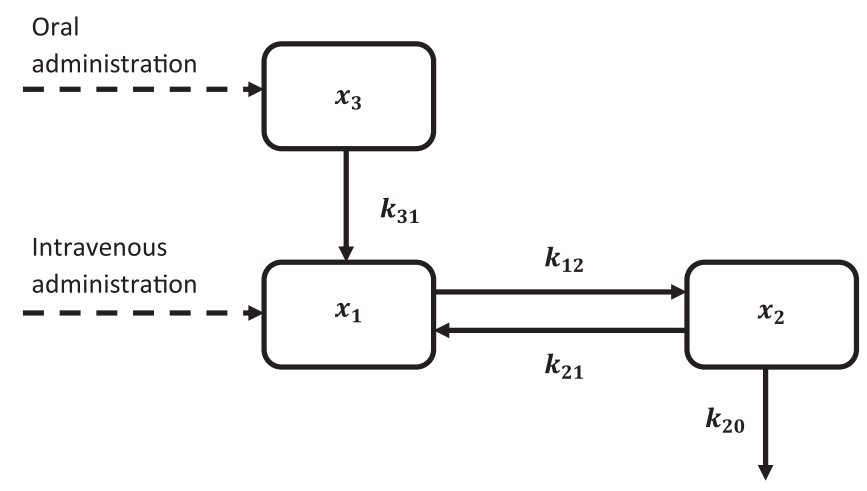

Figure 1. General scheme of the two-compartment model. 
Table 1. Digoxin concentration in three subjects at various times after oral administration of $500 \mu \mathrm{g}$.

\begin{tabular}{|c|c|c|c|c|c|}
\hline \multicolumn{2}{|c|}{$\begin{array}{c}\text { Subject } 1 \text { (Male Volunteer/Age: } 52 \\
\text { years/Weight: } 74 \mathrm{~kg} .\end{array}$} & \multicolumn{2}{|c|}{$\begin{array}{c}\text { Subject } 2 \text { (Male Volunteer/Age: } 54 \\
\text { years } / \text { Weight: } 80 \mathrm{~kg} .\end{array}$} & \multicolumn{2}{|c|}{$\begin{array}{c}\text { Subject } 3 \text { (Female Volunteer } / \text { Age } \\
66 \text { years } / \text { Weight } 71 \mathrm{~kg} .\end{array}$} \\
\hline Time (hr.) & $\begin{array}{l}\text { Drug Concentration } \\
(\mathrm{ng} / \mathrm{ml})\end{array}$ & Time (hr.) & $\begin{array}{l}\text { Drug Concentration } \\
(\mathrm{ng} / \mathrm{ml})\end{array}$ & Time (hr.) & $\begin{array}{l}\text { Drug Concentration } \\
(\mathrm{ng} / \mathrm{ml})\end{array}$ \\
\hline 0.2 & 9.3 & 0.3 & 1.9 & 0.2 & 0.1 \\
\hline 0.3 & 9.4 & 0.4 & 2.1 & 0.3 & 0.6 \\
\hline 0.6 & 6.5 & 0.5 & 2.4 & 0.5 & 1.6 \\
\hline 0.8 & 4.9 & 0.8 & 2.7 & 0.8 & 1.7 \\
\hline 1.0 & 3.8 & 1.0 & 2.6 & - & - \\
\hline 1.5 & 1.7 & 1.5 & 1.3 & 1.5 & 1.8 \\
\hline 2.0 & 1.2 & 2.0 & 0.9 & 2.1 & 1.6 \\
\hline 3.3 & 1.0 & 3.0 & 0.6 & 3.0 & 1.1 \\
\hline 6.3 & 0.5 & 6 & 0.3 & 5.8 & 0.6 \\
\hline
\end{tabular}

Note: K.E. Andersson, Nyberg, Dencker, and Gothlin (1975).

through oral (p.o.) and intravenous (i.v.). Two normal male and one female adult volunteers ages 52 years, 54 years and 66 years, weights 74, 80 and $71 \mathrm{~kg}$ were, respectively, selected for oral (p.o.) study. Three adult subjects C.J., T.F. and W. S. ages 24 years, 26 years and 28 years, weights $75,72.7$ and $77.3 \mathrm{~kg}$ were also selected for the intravenous study. Digoxin was administered at a dose of $500 \mu \mathrm{g}$ by oral (p.o.) and $1 \mathrm{mg}$ dose of digoxin was administered by intravenous (i.v.), then blood samples were withdrawn over a period of $6 \mathrm{~h}$. These data are shown in Table 1 (p.o.) and Table 2 (i.v.). In this study, we considered digoxin as a drug and method of residuals used for identifying the rate constants from the clinical data.

Digoxin: Digoxin is a cardiac glycoside indicated for the treatment of mild-to-moderate heart failure. Most frequently, it is used for atrial fibrillation, atrial flutter and heart failure. Digoxin is taken by mouth or by injection into a vein. Digoxin is extracted from the leaves of Digitalis lanata. The term 'digitalis' is used to designate the whole group of glycosides. The glycosides are composed of 2 portions: a sugar and a cardenolide. Digoxin is described chemically as $(3 \beta, 5 \beta, 12 \beta)$-3-[O-2, 6-dideoxy- $\beta$-D-ribohexopyranosyl-( $1 \rightarrow 4)$-O-2, 6-dideoxy- $\beta$-D-ribo-hexopyranosyl- $(1 \rightarrow 4)$-2, 6-dideoxy- $\beta$ D-ribo-hexopyranosyl) oxy]-12, 14-dihydroxy-card-20(22)-enolide. Its molecular formula is $\mathrm{C}_{41} \mathrm{H}_{64} \mathrm{O}_{14}$, its molecular weight is 780.95 , and its structural formula is:

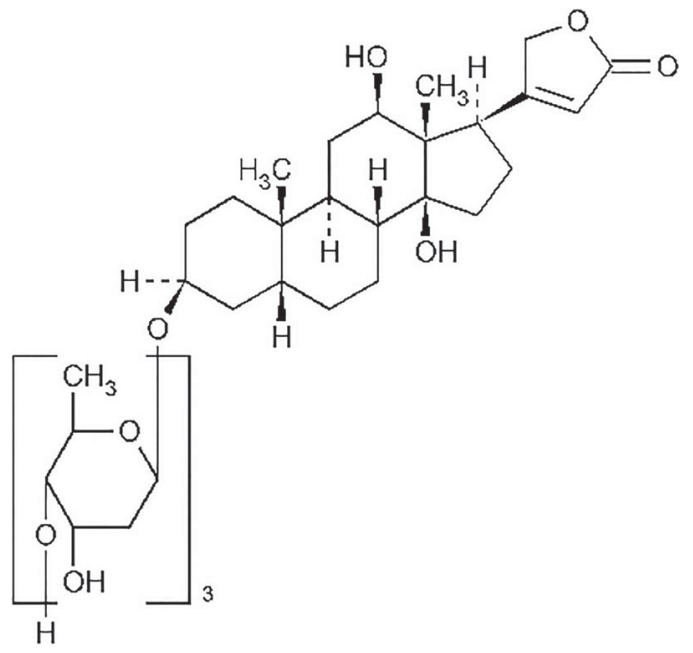


Method of Residuals: The method of residuals is a commonly employed technique for resolving a curve into various exponential terms. This method allows the separation of the mono-exponential constituents of a bi-exponential plot of plasma concentration against time and therefore, it is a useful procedure for fitting a curve to the experimental data of a drug.

As mentioned in this paper, a bi-exponential equation is derived, which is in the form of

$$
x_{1}(t)=A e^{-\lambda_{1} t}+B e^{-\lambda_{2} t}
$$

Here the constants $\lambda_{1}$ and $\lambda_{2}$ are rate constants for the distribution phase and elimination phase, respectively. The constants $A$ and $B$ are intercepts on the $y$-axis for each exponential segment of the curve in the above equation. Clearly, for the data given the decline in the initial distribution phase is more rapid than the elimination phase. The rapid distribution phase is confirmed with the constant $\lambda_{1}$ being larger than the rate constants $\lambda_{2}$. Therefor at a time following the attainment of distribution equilibrium, the term $A e^{-\lambda_{1} t}$ will approach to zero, while $B e^{-\lambda_{2} t}$ will still have a finite value. At this later time, the above equation will reduce to

$$
x_{1}(t)=B e^{-\lambda_{2} t}
$$

Which, in common logarithm, is:

$$
\log x_{1}(t)=\log B-\frac{\lambda_{2} t}{2.3}
$$

Here the rate constant can be obtained from the slope $\left(-\left(\lambda_{2} / 2.3\right)\right)$ of a straight line representing the terminal exponential phase or $\lambda_{2}$ phase is extrapolated to the $y$-axis; the $y$ intercept is equal to $B$. values from the extrapolated line are then subtracted from the original experimental data points and a straight line is obtained. This line represents the rapidly distributed $\lambda_{1}$ phase or the residual plasma concentration against time. A number of pharmacokinetic parameters derived by using rate constants $\lambda_{1}$ and $\lambda_{2}$ and y intercepts $A$ and $B$.

\section{Mathematical method}

\subsection{Assumptions and model building}

A two-compartment model consists of two physiological meaningful parts (Kwon, 2001). The first central compartment $x_{1}$ is identified with the blood and organs were heavily supplied with blood like liver or kidney. The second peripheral compartment $x_{2}$ describes a tissue or the part of the body which is not heavily supplied with blood such as skin and fat tissue. Only, in the case of $p$. o. administration $x_{3}$ describes the absorption compartment in which the absorption takes place. The central and peripheral compartments are connected with each other in both directions and therefore, a distribution between the central and peripheral compartment takes place.

The main assumption in pharmacokinetics is that the drug is completely eliminated from the body through the central compartment. In most cases, the metabolism takes place in the liver and the excretion via the kidneys. 
We consider two different types of drug administration, first, the drug is directly administered by intravenous bolus injection (i.v.) into the blood. It is assumed that the drug is immediately completely distributed in the blood. Second, the drug is orally (p. o.) administered by a tablet. Hence, absorption through the stomach takes place. Therefore, the distribution is not immediate further, only a part of the amount of drug will reach the blood circulation called bio-availability. A schematic overview of the two-compartment model is presented in Figure 1.

To shorten the notations, we consider i. $v$. and p. $o$. administration at once. The general form of a two-compartment model describing either $i$. $v$. or $p$. o. drug administration is given by the set of ODEs as follows:

$$
\begin{aligned}
& \frac{\mathrm{d} x_{1}(t)}{\mathrm{d} t}=-k_{12} x_{1}+k_{21} x_{2}+k_{31} x_{3} ; x_{1}(0)=k_{01} \\
& \frac{\mathrm{d} x_{2}(t)}{\mathrm{d} t}=k_{12} x_{1}-\left(k_{20}+k_{21}\right) x_{2} ; x_{2}(0)=0 \\
& \frac{\mathrm{d} x_{3}(t)}{\mathrm{d} t}=-k_{31} x_{3} ; x_{3}(0)=f . k_{03}
\end{aligned}
$$

Equation (1) describes the central compartment, Equation (2) the peripheral compartment and Equation (3) the absorption in the case of $p$. $o$. administration. Note that the third absorption compartment for p.o. does not count for the nomenclature of the model. Table 3 describes the parameters and variables used in this model. Also, Table 4 describes the particular setting for Equations (1)-(3) to present either p.o. or i.v administration.

\subsection{Case I: Oral administration (p. o.)}

In matrix notation of (1)-(3), we have

$$
\frac{\mathrm{d} X(t)}{\mathrm{d} t}=K X(t)
$$

\begin{tabular}{|c|c|c|c|c|c|}
\hline \multicolumn{2}{|r|}{ C.J. } & \multicolumn{2}{|r|}{ T. F. } & \multicolumn{2}{|r|}{ W.S. } \\
\hline Time (hr.) & $\begin{array}{l}\text { Digoxin Concentration } \\
\text { (ng } / \mathrm{ml})\end{array}$ & Time (hr.) & $\begin{array}{l}\text { Digoxin Concentration } \\
(\mathrm{ng} / \mathrm{ml})\end{array}$ & Time (hr.) & $\begin{array}{c}\text { Digoxin Concentration } \\
(\mathrm{ng} / \mathrm{ml})\end{array}$ \\
\hline 0.03 & 21.0 & 0.03 & 26.5 & 0.03 & 22.0 \\
\hline 0.07 & 22.0 & 0.07 & 21.0 & 0.07 & 18.0 \\
\hline 0.10 & 18.0 & 0.10 & 18.8 & 0.10 & 20.5 \\
\hline 0.13 & 15.0 & 0.13 & 16.5 & 0.13 & 18.5 \\
\hline 0.17 & 15.5 & 0.17 & 14.3 & 0.17 & 16.5 \\
\hline 0.23 & 14.0 & 0.23 & 14.0 & 0.23 & 16.5 \\
\hline 0.30 & 11.3 & 0.30 & 13.0 & 0.30 & 11.5 \\
\hline 0.37 & 13.5 & 0.37 & 12.3 & 0.37 & 13 \\
\hline 0.50 & 12.5 & 0.50 & 10.3 & 0.50 & 9.8 \\
\hline 0.75 & 9.1 & 0.75 & 7.6 & 0.75 & 7.3 \\
\hline 1.00 & 6.7 & 1.00 & 5.8 & 1.00 & 5.5 \\
\hline 2.00 & 3.6 & 2.00 & 3.3 & 2.00 & 2.8 \\
\hline 3.00 & 2.6 & 3.00 & 2.2 & 3.00 & 2 \\
\hline 4.00 & 2.2 & 4.00 & 1.9 & 4.00 & 1.4 \\
\hline 6.00 & 1.2 & 6.00 & 0.52 & 6.00 & 0.73 \\
\hline
\end{tabular}

Table 2. Digoxin concentration in three patients C. J., T. F and W.S. at various times after intravenous administration of $1 \mathrm{mg}$.

Note: William G. Kramer et al. (1974). 
Table 3. Parameters and variables present in the model.

\begin{tabular}{|c|c|}
\hline $\begin{array}{l}\text { Parameters } \\
\text { and variables }\end{array}$ & Description \\
\hline$k_{12}$ & the rate of flow of digoxin from the central compartment to the peripheral compartment \\
\hline$k_{21}$ & the rate of flow of digoxin from the peripheral compartment to the central compartment \\
\hline$k_{20}$ & the excretion from the peripheral compartment \\
\hline$k_{31}$ & the absorption rate of digoxin in case of $p . o$. \\
\hline$k_{01}$ & the dose of digoxin either in the p.o. or i.v. administration \\
\hline$x_{1}(t)$ & the digoxin concentration in the central compartment at a time $t$ \\
\hline$x_{2}(t)$ & the digoxin concentration in the peripheral compartment at a time $t$ \\
\hline$x_{3}(t)$ & the digoxin concentration in the absorption compartment at a time $t$ \\
\hline $0<f \leq 1$ & $\begin{array}{l}\text { Fraction parameter regulating the amount of drug which effectively reaches the blood in case of p. } 0 \text {. } \\
\text { administration. We set } f=1 \text { without loss of generality for our mathematical consideration. }\end{array}$ \\
\hline
\end{tabular}

Table 4. Particular settings for Equations (1)-(3) to present either p.o. or i.v. administration.

\begin{tabular}{ll}
\hline p.o. administration & \multicolumn{1}{c}{ i.v. administration } \\
\hline$k_{12}, k_{21}, k_{20}, k_{31}>0$ & $k_{12}, k_{21}, k_{20}>0$ and $k_{31}=$ does not exit \\
$X(0)=\left(0,0, k_{03}\right)^{T}$ & $X(0)=\left(k_{01}, 0\right)^{T}$ \\
\hline
\end{tabular}

where

$$
X(t)=\left[\begin{array}{l}
x_{1}(t) \\
x_{2}(t) \\
x_{3}(t)
\end{array}\right] \text { and } K=\left[\begin{array}{ccc}
-k_{12} & k_{21} & k_{31} \\
k_{12} & -\left(k_{20}+k_{21}\right) & 0 \\
0 & 0 & -k_{31}
\end{array}\right]
$$

The Laplace transform (Doetsch 1976; Widder, 1966) is an integral transform where the linear operator $\mathcal{L}\{f(t)\}$ transform a function $f(t)$ with $t \in \mathbb{R}$ from the time domain to a function $F(s)$ with $s \in \mathbb{C}$ in an image domain. The advantage of this transformation is that differentiation and integration in the time domain correspond to simple algebraic operations in the image domain.

To solve (4), apply Laplace Transform, which gives

$$
\begin{aligned}
\mathcal{L}\left\{X^{\prime}(t)\right\}=\mathcal{L}\{K X\} & \Leftrightarrow s \mathcal{L}\{X(t)\}-X(0)=K \mathcal{L}\{X(t)\} \\
& \Leftrightarrow(s I-K) \mathcal{L}\{X(t)\}=X(0) \\
& \Leftrightarrow\left[\begin{array}{ccc}
s+k_{12} & -k_{21} & -k_{31} \\
-k_{12} & s+k_{20}+k_{21} & 0 \\
0 & 0 & s+k_{31}
\end{array}\right]\left[\begin{array}{c}
\mathcal{L}\left\{x_{1}(t)\right\} \\
\mathcal{L}\left\{x_{2}(t)\right\} \\
\mathcal{L}\left\{x_{3}(t)\right\}
\end{array}\right]=\left[\begin{array}{c}
0 \\
0 \\
k_{03}
\end{array}\right] \\
& \Leftrightarrow L(s) \cdot \mathcal{L}\{X(t)\}=X(0)
\end{aligned}
$$

where

$$
L(s)=\left[\begin{array}{ccc}
s+k_{12} & -k_{21} & -k_{31} \\
-k_{12} & s+k_{20}+k_{21} & 0 \\
0 & 0 & s+k_{31}
\end{array}\right]
$$


We solve the system of Equation (6) by Cramer's rule.

$$
\begin{aligned}
\operatorname{det}(L(s)) & =\operatorname{det}(s I-K)=\left(s+k_{31}\right)\left[\left(s+k_{12}\right)\left(s+k_{20}+k_{21}\right)-k_{12} k_{21}\right] \\
& =\left(s+k_{31}\right)\left[s^{2}+\left(k_{12}+k_{21}+k_{20}\right) s+k_{12} k_{20}\right] \\
& =\left(s+k_{31}\right)\left[s^{2}+\left(\lambda_{1}+\lambda_{2}\right) s+\lambda_{1} \lambda_{2}\right] \\
& =\left(s+k_{31}\right)\left(s+\lambda_{1}\right)\left(s+\lambda_{2}\right)
\end{aligned}
$$

where $\lambda_{1}>0, \lambda_{2}>0$ and are real therefore, $\operatorname{det}(L(s))=\left(s+k_{31}\right)\left(s+\lambda_{1}\right)\left(s+\lambda_{2}\right)>$ $0 \forall s \geq 0$

$$
\lambda_{1}+\lambda_{2}=k_{12}+k_{21}+k_{20} \text { and } \lambda_{1} \lambda_{2}=k_{12} k_{20}
$$

To calculate the solution of the central compartment $x_{1}(t)$, peripheral compartment $x_{2}(t)$ and absorption compartment $x_{3}(t)$ in p.o. case, we substitute the vector $X(0)$ from Table 4 into the first column, second column and third column of the matrix $L(s)$ and denote the resulting matrices by $L_{1}(s), L_{2}(s)$ and $L_{3}(s)$ respectively, the quotient from Cramer's rule, we obtain.

$$
\mathcal{L}\left\{x_{1}(t)\right\}=\frac{\operatorname{det}\left(L_{1}(s)\right)}{\operatorname{det}(L(s))}, \mathcal{L}\left\{x_{2}(t)\right\}=\frac{\operatorname{det}\left(L_{2}(s)\right)}{\operatorname{det}(L(s))} \text { and } \mathcal{L}\left\{x_{3}(t)\right\}=\frac{\operatorname{det}\left(L_{3}(s)\right)}{\operatorname{det}(L(s))}
$$

Making use of inverse Laplace Transform, Equations (7) and (9) give

$$
\begin{aligned}
& x_{1}(t)=\mathcal{L}^{-1}\left\{\frac{k_{03} k_{31}\left(s+k_{20}+k_{21}\right)}{\left(s+k_{31}\right)\left(s+\lambda_{1}\right)\left(s+\lambda_{2}\right)}\right\} \\
& x_{2}(t)=\mathcal{L}^{-1}\left\{\frac{k_{12} k_{03} k_{31}}{\left(s+k_{31}\right)\left(s+\lambda_{1}\right)\left(s+\lambda_{2}\right)}\right\} \\
& x_{3}(t)=\mathcal{L}^{-1}\left\{\frac{k_{03}}{\left(s+k_{31}\right)}\right\}
\end{aligned}
$$

Applying Heaviside's Theorem to Equations (10)-(12) to obtain the solution

$$
\begin{aligned}
x_{1}^{p o}(t)= & \frac{k_{03} k_{31}\left(k_{20}+k_{21}-\lambda_{1}\right)}{\left(k_{31}-\lambda_{1}\right)\left(\lambda_{2}-\lambda_{1}\right)} e^{-\lambda_{1} t}+\frac{k_{03} k_{31}\left(k_{20}+k_{21}-\lambda_{2}\right)}{\left(k_{31}-\lambda_{2}\right)\left(\lambda_{1}-\lambda_{2}\right)} e^{-\lambda_{2} t} \\
& +\frac{k_{03} k_{31}\left(k_{20}+k_{21}-k_{31}\right)}{\left(\lambda_{1}-k_{31}\right)\left(\lambda_{2}-k_{31}\right)} e^{-k_{31} t} \\
x_{2}{ }^{p o}(t)= & \frac{k_{12} k_{03} k_{31}}{\left(k_{31}-\lambda_{1}\right)\left(\lambda_{2}-\lambda_{1}\right)} e^{-\lambda_{1} t}+\frac{k_{12} k_{03} k_{31}}{\left(k_{31}-\lambda_{2}\right)\left(\lambda_{1}-\lambda_{2}\right)} e^{-\lambda_{2} t} \\
& +\frac{k_{12} k_{03} k_{31}}{\left(\lambda_{1}-k_{31}\right)\left(\lambda_{2}-k_{31}\right)} e^{-k_{31} t}
\end{aligned}
$$

Equation (12) gives the solution of absorption compartment.

$$
x_{3}^{p o}(t)=k_{03} e^{-k_{31} t}
$$




\subsubsection{Case II: Intravenous administration (i. v.)}

Since the third compartment does not exist for the intravenous administration, the matrix notation of Equations (1) and (2) from Equation (4), we have.

$$
X(t)=\left[\begin{array}{l}
x_{1}(t) \\
x_{2}(t)
\end{array}\right] \text { and } K=\left[\begin{array}{cc}
-k_{12} & k_{21} \\
k_{12} & -\left(k_{20}+k_{21}\right)
\end{array}\right]
$$

From Equation (6),

$$
L(s)=\left[\begin{array}{cc}
s+k_{12} & -k_{21} \\
-k_{12} & s+k_{20}+k_{21}
\end{array}\right]
$$

where

$$
\begin{aligned}
\operatorname{det}(L(s)) & =\operatorname{det}(s I-K)=\left(s+k_{12}\right)\left(s+k_{20}+k_{21}\right)-k_{12} k_{21} \\
& =s^{2}+\left(k_{12}+k_{21}+k_{20}\right) s+k_{12} k_{20} \\
& =s^{2}+\left(\lambda_{1}+\lambda_{2}\right) s+\lambda_{1} \lambda_{2} \\
& =\left(s+\lambda_{1}\right)\left(s+\lambda_{2}\right)
\end{aligned}
$$

Here, $\lambda_{1}>0, \lambda_{2}>0$ and are real therefore, $\operatorname{det}(L(s))=\left(s+\lambda_{1}\right)\left(s+\lambda_{2}\right)>0 \forall s \geq 0$

To calculate the solution of the central compartment $x_{1}(t)$, peripheral compartment $x_{2}(t)$ in $i . v$. case. We substitute the vector $X(0)$ from Table 4 into the first column and second column of the matrix $L(s)$ in (16) and denote the resulting matrices by $M_{1}(s), M_{2}(s)$ respectively, the quotient from Cramer's rule, we obtain.

$$
\mathcal{L}\left\{x_{1}(t)\right\}=\frac{\operatorname{det}\left(M_{1}(s)\right)}{\operatorname{det}(L(s))}, \mathcal{L}\left\{x_{2}(t)\right\}=\frac{\operatorname{det}\left(M_{2}(s)\right)}{\operatorname{det}(L(s))}
$$

Making use of inverse Laplace Transform,

$$
\begin{aligned}
& x_{1}(t)=\mathcal{L}^{-1}\left\{\frac{k_{01}\left(s+k_{20}+k_{21}\right)}{\left(s+\lambda_{1}\right)\left(s+\lambda_{2}\right)}\right\} \\
& x_{2}(t)=\mathcal{L}^{-1}\left\{\frac{k_{01} k_{12}}{\left(s+\lambda_{1}\right)\left(s+\lambda_{2}\right)}\right\}
\end{aligned}
$$

Applying Heaviside's Theorem to Equations (19) and (20) to obtain the solution

$$
\begin{aligned}
& x_{1}^{i v}(t)=\frac{k_{01}\left(\lambda_{2}-k_{12}\right)}{\left(\lambda_{2}-\lambda_{1}\right)} e^{-\lambda_{1} t}+\frac{k_{01}\left(\lambda_{1}-k_{12}\right)}{\left(\lambda_{1}-\lambda_{2}\right)} e^{-\lambda_{2} t} \\
& x_{2}{ }^{i v}(t)=\frac{k_{01} k_{12}}{\left(\lambda_{2}-\lambda_{1}\right)} e^{-\lambda_{1} t}+\frac{k_{01} k_{12}}{\left(\lambda_{1}-\lambda_{2}\right)} e^{-\lambda_{2} t}
\end{aligned}
$$

\section{Clinical application}

\subsection{Results - oral administration}

Once the pharmacokinetic parameters in Table 5 are determined using the method of residuals for an individual, the amount of drug remaining in the central and peripheral 
Table 5. Parameters and RMSE of Subject 1, Subject 2 and Subject 3.

\begin{tabular}{lccc}
\hline Parameters & Subject 1 & Subject 2 & Subject 3 \\
\hline $\boldsymbol{k}_{12}$ & 1.8722 & 1.4443 & 1.5716 \\
$\boldsymbol{k}_{20}$ & 0.1327 & 0.0704 & 0.1972 \\
$\boldsymbol{k}_{21}$ & 0.1323 & 1.0971 & 0.8712 \\
$\boldsymbol{k}_{31}$ & 8.2753 & 2.0550 & 2.1966 \\
RMSE & 0.1697 & 0.0974 & 0.1282 \\
\hline
\end{tabular}

Table 6. Simulated and actual digoxin concentrations in the central compartment of Subject 1, Subject 2 and Subject 3 after oral administration of $500 \mu \mathrm{g}$.

\begin{tabular}{|c|c|c|c|c|c|c|c|c|c|}
\hline \multicolumn{10}{|c|}{ Subject 1 (Male volunteer /Age: 52 years/Weight: 74 kg. } \\
\hline Time (hr.) & 0.2 & 0.3 & 0.6 & 0.8 & 1.0 & 1.5 & 2.0 & 3.3 & 6.3 \\
\hline Actual (ng/ml) & 9.3 & 9.4 & 6.5 & 4.9 & 3.8 & 1.7 & 1.2 & 1.0 & 0.5 \\
\hline x1-Simulated (ng/ml) & 9.3435 & 9.2553 & 6.7675 & 4.8199 & 3.5665 & 1.8801 & 1.2865 & 0.8239 & 0.5645 \\
\hline \multicolumn{10}{|c|}{ Subject 2 (Male Volunteer/Age: 54 years/Weight: 80 kg. } \\
\hline Time (hr.) & 0.3 & 0.4 & 0.5 & 0.8 & 1.0 & 1.5 & 2.0 & 3.0 & 6 \\
\hline Actual (ng/ml) & 1.9 & 2.1 & 2.4 & 2.7 & 2.6 & 1.3 & 0.9 & 0.6 & 0.3 \\
\hline x1-Simulated (ng/ml) & 1.9918 & 2.1406 & 2.4461 & 2.7466 & 2.5085 & 1.3948 & 1.0949 & 0.5217 & 0.2921 \\
\hline \multicolumn{10}{|c|}{ Subject 3 (Female volunteer / Age: 66 years/Weight: 71 kg. } \\
\hline Time (hr.) & 0.2 & 0.3 & 0.5 & 0.8 & - & 1.5 & 2.1 & 3.0 & 5.8 \\
\hline Actual (ng /ml) & 0.1 & 0.6 & 1.6 & 1.7 & - & 1.8 & 1.6 & 1.1 & 0.6 \\
\hline x1-Simulated (ng /ml) & 0.0442 & 0.7859 & 1.3681 & 1.8467 & - & 1.7566 & 1.5208 & 1.1973 & 0.5701 \\
\hline
\end{tabular}

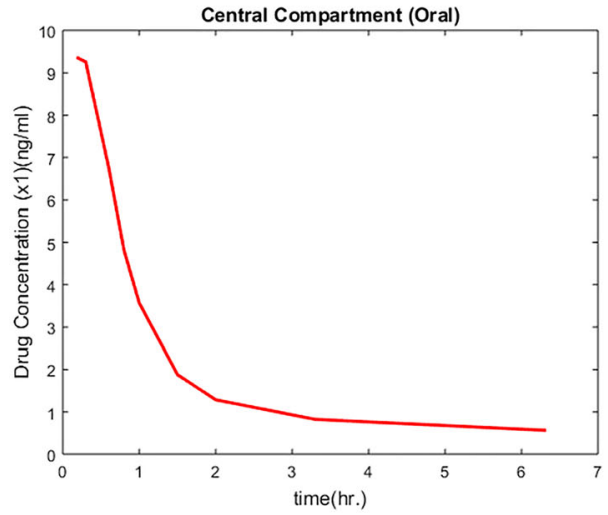

(a)

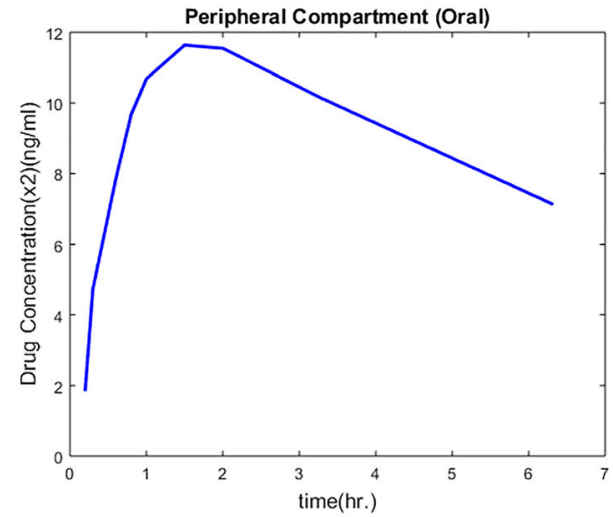

(b)

Figure 2. Subject 1: Digoxin concentration in the central compartment (a) and peripheral compartment (b) after oral administration of $500 \mu \mathrm{g}$.

compartments is calculated using Equations (12) and (13). The pharmacokinetic data for digoxin are calculated in Subject 1, Subject 2 and Subject 3. Simulated and actual digoxin concentrations in the central compartment of Subject 1, Subject 2 and Subject 3 are tabulated in Table 6 and plotted for Subject 1 in Figure 2(a) (Central Compartment), Figure 2(b) (Peripheral Compartment) and Figure 5(a) (Actual and Simulated data in Central Compartment). For Subject 2, Figure 3(a) (Central Compartment), Figure 3(b) (Peripheral Compartment) and Figure 5(b) (Actual and Simulated data in Central Compartment) are plotted. Also, plotted for Subject 3 in Figure 4(a) (Central Compartment), Figure 4(b) (Peripheral Compartment) and Figure 5(c) (Actual and Simulated data in Central Compartment). During the first hour after oral administration of digoxin, a peak was 


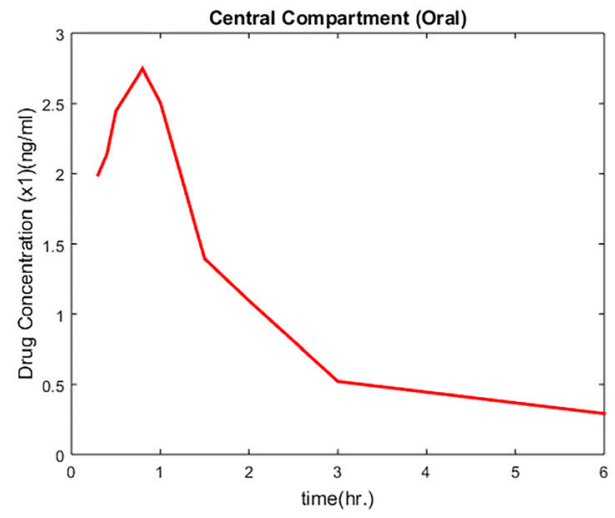

(a)

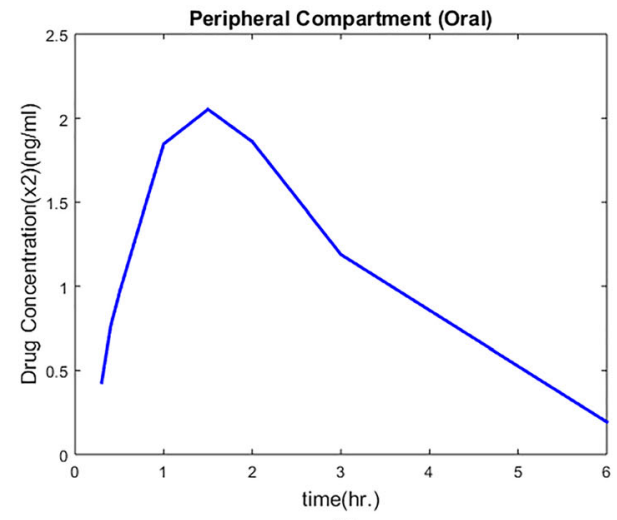

(b)

Figure 3. Subject 2: Digoxin concentration in the central compartment (a) and peripheral compartment (b) after oral administration of $500 \mu \mathrm{g}$.

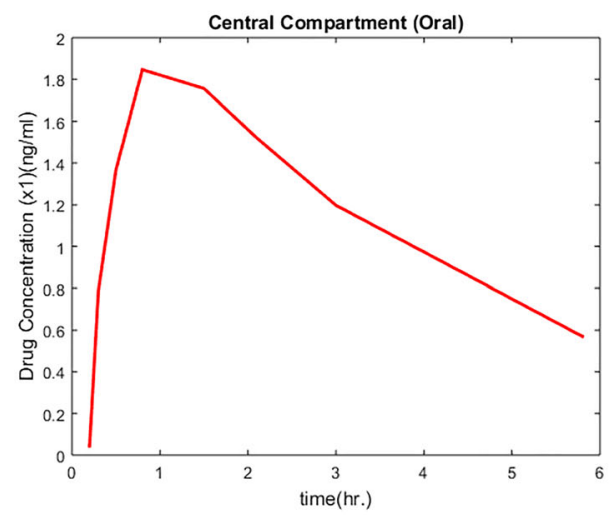

(a)

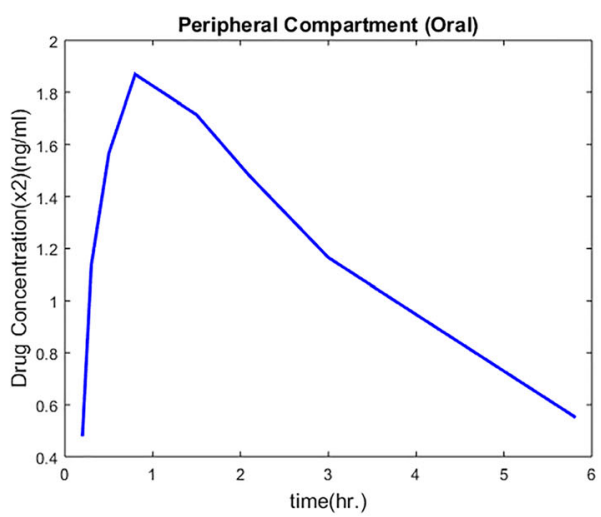

(b)

Figure 4. Subject 3: Digoxin concentration in the central compartment (a) and peripheral compartment (b) after oral administration of $500 \mu \mathrm{g}$.

found in all the three subjects and the same is illustrated in Figure 2(a). and Figure 3(a). In Subject 1 it takes $0.2 \mathrm{~h}$ to reach the high concentration of $9.3435 \mathrm{ng} / \mathrm{ml}$ whereas, in Subject 2 and Subject 3 it takes $0.8 \mathrm{~h}$ to reach the high concentration of $2.7466 \mathrm{ng} / \mathrm{ml}$ and $1.8467 \mathrm{ng} / \mathrm{ml}$, respectively. However, within $1.5 \mathrm{~h}$ the digoxin concentration falls to $1.8801 \mathrm{ng} / \mathrm{ml}$ and $1.3948 \mathrm{ng} / \mathrm{ml}$ for Subject 1 and Subject 2, respectively and also within $2.1 \mathrm{~h}$ the digoxin concentration falls to $1.5208 \mathrm{ng} / \mathrm{ml}$ for Subject 3. The rate of disintegration of digoxin is very slow after 1.5 hours in both Subject 1 and Subject 2, whereas in Subject 3 it is slow down after $2.1 \mathrm{~h}$. It takes almost $6-7 \mathrm{~h}$ to reduce from $1.8801 \mathrm{ng} / \mathrm{ml}$ to $0.5645 \mathrm{ng} / \mathrm{ml}$ in Subject 1 and $1.3948 \mathrm{ng} / \mathrm{ml}$ to $0.2921 \mathrm{ng} / \mathrm{ml}$ in Subject 2 also, in Subject 3 it reduces from 1.5208 to $0.5701 \mathrm{ng} / \mathrm{ml}$. In the peripheral compartment of three subjects, the digoxin concentration quickly raises in the span of $1-1.5 \mathrm{~h}$, then slowly decreases in the next $4.5 \mathrm{~h}$. More clearly, the digoxin concentration of Subject 1 in the peripheral compartment (Figure 2(b)) increases from 1.8881 to $11.6384 \mathrm{ng} / \mathrm{ml}$ in the span of $1.5 \mathrm{~h}$ and takes $4.8 \mathrm{~h}$ to reduce $7.1440 \mathrm{ng} / \mathrm{ml}$. In Subject 2, the dioxin concentration in the peripheral 


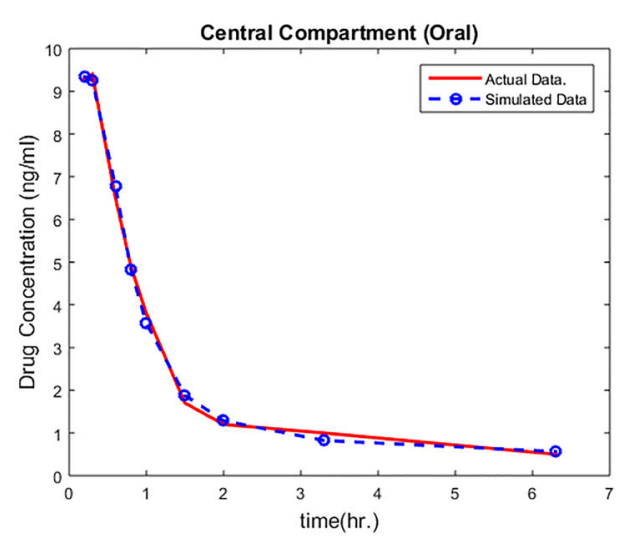

(a)

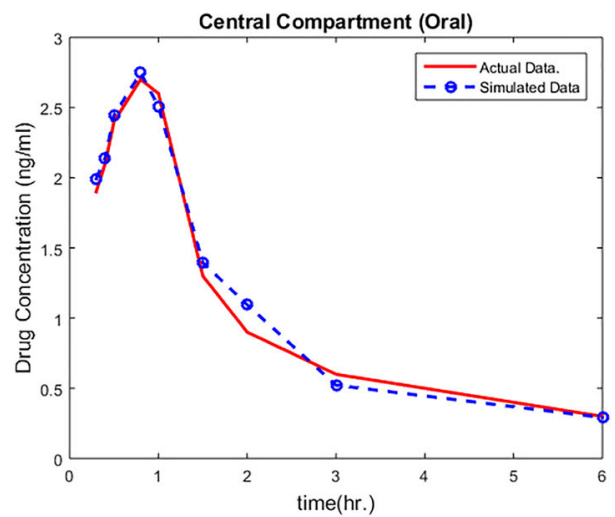

(b)

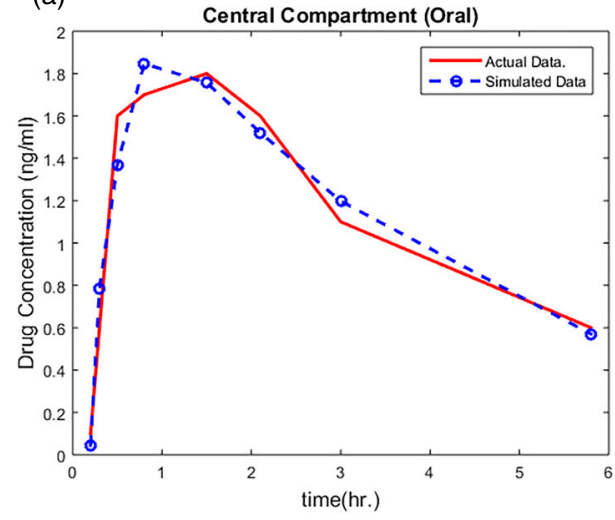

(c)

Figure 5. Simulated and actual digoxin concentrations in the central compartment of Subject 1 (a), Subject 2 (b) and Subject 3 (c) after oral administration of $500 \mu \mathrm{g}$.

compartment (Figure 3(b)) increases from 0.4293 to $2.0535 \mathrm{ng} / \mathrm{ml}$ in $1.5 \mathrm{~h}$ and takes $4.5 \mathrm{~h}$ to reduce $0.1936 \mathrm{ng} / \mathrm{ml}$. However, in Subject 3, the digoxin concentration in the peripheral compartment (Figure $4(\mathrm{~b})$ ) increases from 0.4845 to $1.8689 \mathrm{ng} / \mathrm{ml}$ in $0.8 \mathrm{~h}$ and takes $5.8 \mathrm{~h}$ to reduce $0.5548 \mathrm{ng} / \mathrm{ml}$.

\subsection{Results - intravenous administration}

The pharmacokinetic parameters in Table 7 are determined using the method of residuals for an individual, the amount of drug remaining in the central and peripheral compartments is calculated using Equations (20) and (21). The pharmacokinetic data for

Table 7. Parameters and RMSE of C. J., T. F. and W. S.

\begin{tabular}{lccc}
\hline Parameters & C. J. & T. F. & W. S. \\
\hline $\boldsymbol{k}_{12}$ & 2.8421 & 8.0646 & 2.8366 \\
$\boldsymbol{k}_{20}$ & 2.7418 & 3.1652 & 3.3874 \\
$\boldsymbol{k}_{21}$ & 3.3865 & 4.1291 & 3.3513 \\
RMSE & 0.4993 & 0.4950 & 0.9543 \\
\hline
\end{tabular}




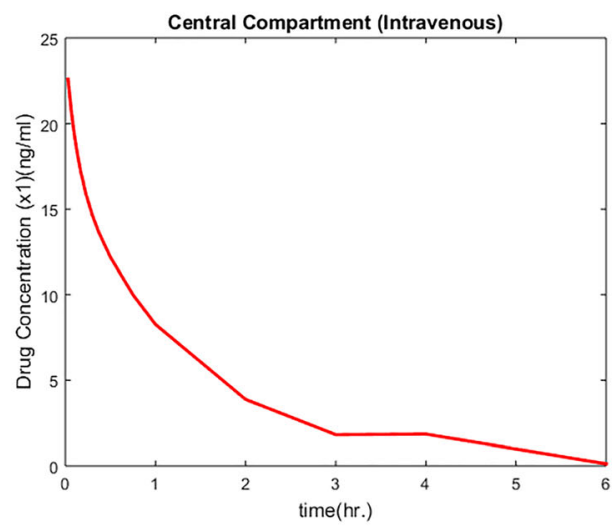

(a)

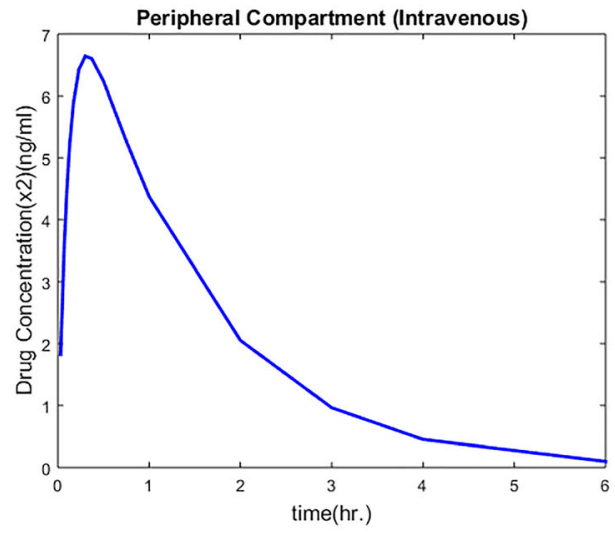

(b)

Figure 6. C. J.: Digoxin concentration in the central compartment (a) and peripheral compartment (b) after intravenous administration of $1 \mathrm{mg}$.

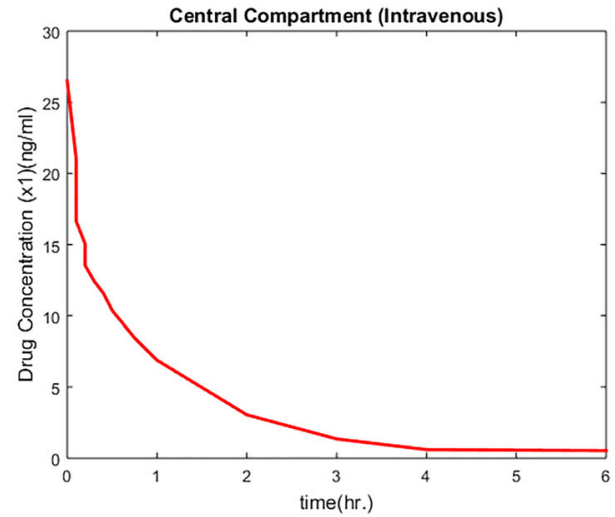

(a)

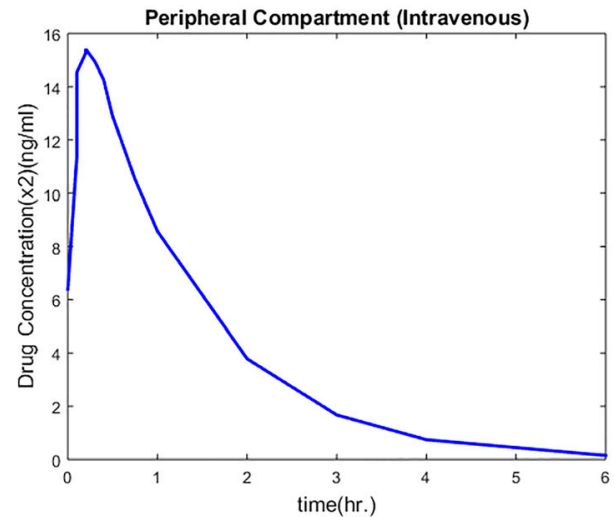

(b)

Figure 7. T. F.: Digoxin concentration in the central compartment (a) and peripheral compartment (b) after intravenous administration of $1 \mathrm{mg}$.

digoxin are calculated in subjects C.J. and T.F. Simulated and actual digoxin concentrations in the central compartment of subjects C.J. and T.F are given in Table 8 and plotted for C. J. in Figure 6(a) (Central Compartment), Figure 6(b) (Peripheral Compartment) and Figure 9(a) (Actual and Simulated data in Central Compartment), also plotted for T.F. in Figure 7(a) (Central Compartment), Figure 7(b) (Peripheral Compartment) and Figure 9(b) (Actual and Simulated data in Central Compartment). When an intravenous dose of digoxin is administered, the digoxin enters directly into the central compartment. It can be seen that digoxin concentration of the central compartment declines rapidly during the initial distribution phase, while digoxin amount in the peripheral compartment equilibrates more slowly in C.J., T.F. and W.S. The digoxin concentration in the central compartment of C.J. (Figure 6(a)), T.F. (Figure 7(a)) and W.S. (Figure 8(a)) decreases rapidly within $1 \mathrm{~h}$ from 22.58 to $8.26 \mathrm{ng} / \mathrm{ml}, 26.50$ to $6.88 \mathrm{ng} / \mathrm{ml}$ and 21.56 to $5.48 \mathrm{ng} / \mathrm{ml}$, respectively. In the next 6 hours, the concentration of digoxin slowly decreases to $0.12 \mathrm{ng} / \mathrm{ml}$, 


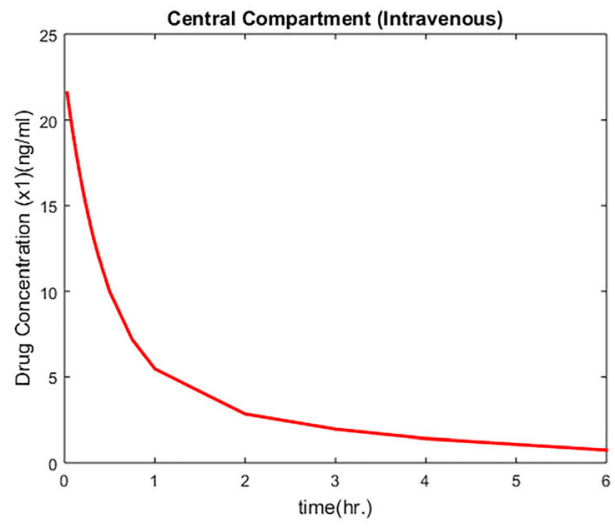

(a)

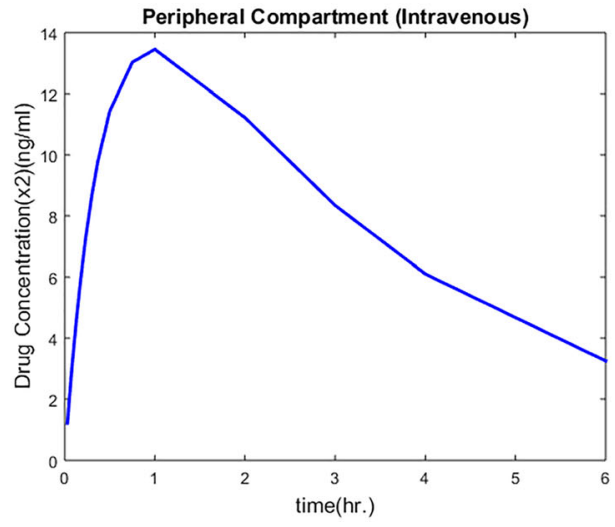

(b)

Figure 8. W. S.: Digoxin concentration in the central compartment (a) and peripheral compartment (b) after intravenous administration of $1 \mathrm{mg}$.

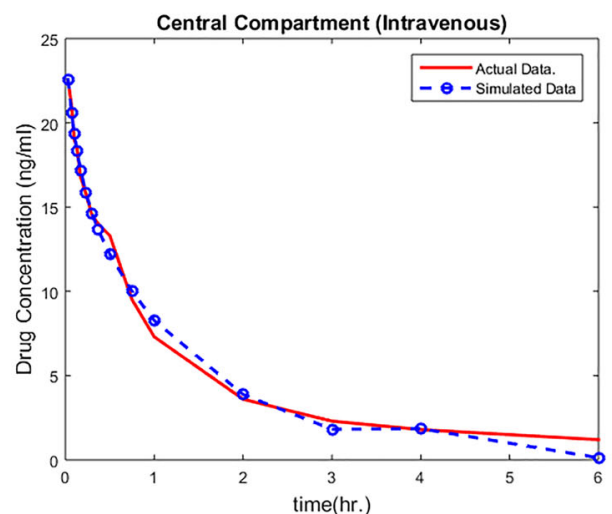

(a)

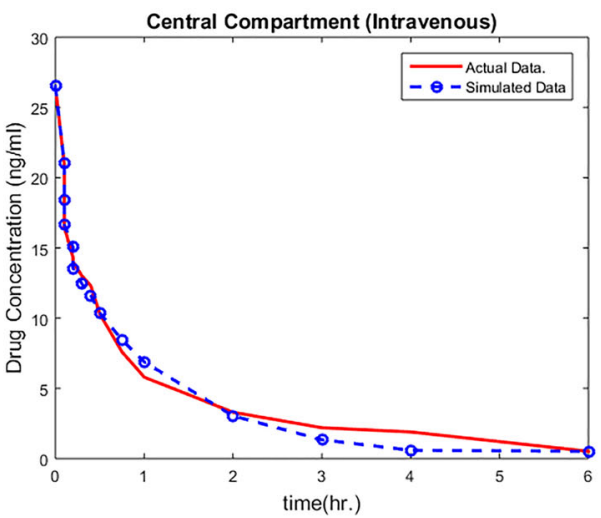

(b)

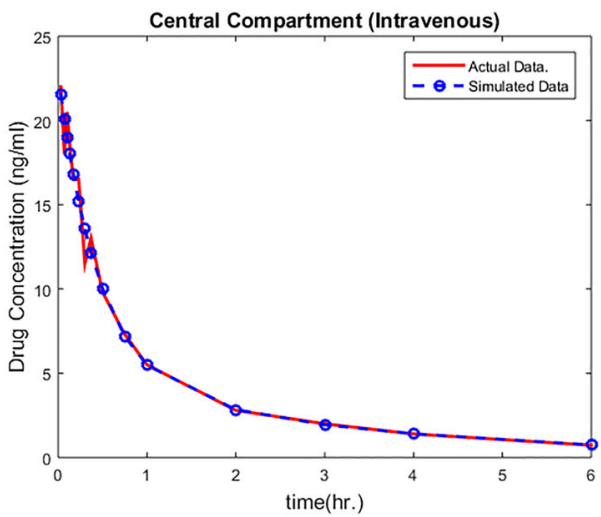

(c)

Figure 9. Simulated and actual digoxin concentrations in central compartment of C. J. (a), T. F. (b) and W. S. (c) after intravenous administration of $1 \mathrm{mg}$. 
Table 8. Simulated and actual digoxin concentrations in the central compartment of C. J., T. F and W. S.

\begin{tabular}{|c|c|c|c|c|c|c|c|c|c|c|c|c|c|c|c|}
\hline \multicolumn{16}{|c|}{ C.J.Age: 24/Weight: 75} \\
\hline Time (hr.) & 0.03 & 0.07 & 0.10 & 0.13 & 0.17 & 0.23 & 0.30 & 0.37 & 0.50 & 0.75 & 1.00 & 2.00 & 3.00 & 4.00 & \\
\hline 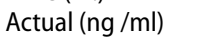 & 22.5 & 21.0 & 19.0 & 18.5 & 16.8 & 15.8 & 14.5 & 14.0 & 13.3 & 9.5 & 7.3 & 3.6 & 2.3 & 1.8 & \\
\hline & 22.58 & & 19.35 & & 17.19 & 15.84 & 14.62 & & 12.18 & 10.00 & 8.26 & 3.87 & 1.81 & 1.85 & \\
\hline \multicolumn{16}{|l|}{ T.F./Age: 26} \\
\hline Im & 0.03 & 0.07 & 0.10 & 0.13 & 0.17 & 0.23 & 0.30 & 0.37 & 0.50 & 0.75 & 1.00 & 2.00 & 3.00 & 4.00 & \\
\hline & & & & & & & & & & & & 3 & 2.2 & 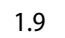 & \\
\hline simua & 26.50 & 21.04 & 18.45 & 16.66 & 15.04 & 13.54 & 12.42 & 11.60 & 10.37 & 8.44 & 6.88 & 3.03 & 1.34 & 0.59 & \\
\hline \multicolumn{16}{|c|}{ eight: 77.3} \\
\hline & 0.03 & & & & & & & & & & & 2 & & 4 & \\
\hline & 22 & 18 & 20.5 & 18.5 & 16.5 & 16.5 & 11.5 & 13 & 9.8 & 7.3 & 5.5 & 2.8 & 2 & 1.4 & \\
\hline Simulated (ng/ml) & 21.56 & 20.06 & 19.02 & 18.04 & 16.83 & 15.21 & 13.56 & 12.14 & 9.99 & 7.19 & 5.48 & 2.84 & 1.95 & 1.41 & \\
\hline
\end{tabular}

$0.51 \mathrm{ng} / \mathrm{ml}$ and $0.75 \mathrm{ng} / \mathrm{ml}$ in C.J., T.F. and W.S, respectively. However, the digoxin concentration of the peripheral compartment in C.J. (Figure 6(b)) increases rapidly from $2.58 \mathrm{ng} / \mathrm{ml}$ and reaches the peak $8.98 \mathrm{ng} / \mathrm{ml}$ within $0.3 \mathrm{~h}$ then it starts decreasing and reaches to $3.38 \mathrm{ng} / \mathrm{ml}$ in $2 \mathrm{~h}$ and it equilibrates. It takes $6 \mathrm{~h}$ to reach $0.28 \mathrm{ng} / \mathrm{ml}$. The digoxin concentration of the peripheral compartment in T.F. (Figure $7(\mathrm{~b})$ ) increases quickly from $1.83 \mathrm{ng} / \mathrm{ml}$ and reaches the highest point $6.64 \mathrm{ng} / \mathrm{ml}$ in $0.3 \mathrm{~h}$ and declines to $2.06 \mathrm{ng} / \mathrm{ml}$ in $2 \mathrm{~h}$ then slowly decrease to $0.10 \mathrm{ng} / \mathrm{ml}$ in $6 \mathrm{~h}$. Also, the digoxin concentration of the peripheral compartment in W.S. (Figure 8(b)) increases quickly from $1.21 \mathrm{ng} / \mathrm{ml}$ and reaches the highest peak of $13.45 \mathrm{ng} / \mathrm{ml}$ in $1 \mathrm{~h}$ then slowly decreases to $3.25 \mathrm{ng} / \mathrm{ml}$ in $6 \mathrm{~h}$.

\section{Conclusion}

In this present study, we develop a two-compartment model and consider digoxin drug administration through oral (p.o.) and intravenous (i.v) to four volunteers. Kramer et al considered a two-compartmental model with excretion from the central compartment and describes the time course of drug concentration in the central compartment model after an intravenous injection, whereas the authors considered excretion from the peripheral compartment for both the oral and intravenous injection. The solution curves for clinical data and model were drawn using MATLAB. In this two-way cross-over study it was noted that the digoxin concentration in the central compartment after oral administration, our model-simulated data almost coincide with the available clinical data (Table 1) with RMSE 0.1697 (Subject 1), 0.0974 (Subject 2) and 0.1282 (Subject 3) which we can see from Figure 4 to Figure 10 of each subject. Also, after the intravenous administration, the data simulated by our model almost coincide with the available clinical data (Table 2) with RMSE 0.4993 (C.J.), 0.4950 (T.F) and 0.9543 (W.S.) which we can see from Figure 13 to Figure 19 of each subject. Eventually, our model predicts the measures of the drug concentration in the peripheral compartment for any given time in both p.o. administration and i.v. administration. Also, we were unable to demonstrate any significant relationship between digoxin doses of $500 \mu \mathrm{g}$ and $1 \mathrm{mg}$ administered through oral and intravenous respectively and the parameters $k_{12}, k_{21}, k_{31}$ and $k_{20}$. This supports the observation that the pharmacokinetics of digoxin when given through oral and intravenous, are independent of dose. Also, there is no significant relation between pharmacokinetic parameters and RMSE of each subject in both the administrations. When we are using a non-linear compartment model 
in pharmacokinetics, the general approach is to use ODEs. Furthermore, stochastic differential equations (SDEs) are achieved by adding a Wiener noise component. This extra noise permits handling of auto-correlated residuals originating from natural variation or a systematic model error. Auto-correlated residuals are often partly ignored in pharmacokinetic modelling although it violates the hypothesis for many standard statistical tests (Klim, Mortensen, Kristensen, Overgaard, \& Madsen, 2009). Since a curved pattern occurs in the residual plots for the deterministic minimal model a stochastic approach could decrease this curve pattern and give more accurate results.

\section{References}

Andersson, K. E., Nyberg, L., Dencker, H., \& Gothlin, J. (1975). Absorption of digoxin in man after oral and intrasigmoid administration studied by portal vein catheterization. European journal of clinical pharmacology, 9(1), 39-47.

Doetsch, G. (1976). Einführung in theorie und anwendung der laplace-transformation (3rd ed.). Basel: Springer Basel AG.

Doherty, J. E., Flanigan, W. J., \& Dalrymple, G. V. (1972). Tritiated digoxin. XVII. Excretion and turnover times in normal donors before and after nephrectomy and in the paired recipients of the kidney after transplantation. The American Journal of Cardiology, 29, 470-74.

Gitfrich, H. J., Bodem, G., \& Chidsey, C. A. (1974). Untersuchungen zur Pharmakokinetik yon Digoxin. Arzneimittel-Forschung, 23, 1659-I660.

Kannan, R., Guo, P., \& Przekwas, A. (2016). Particle transport in the human respiratory tract: formulation of a nodal iinverse distance weighted Eulerian - Lagrangian transport and implementation of the Wind - Kessel algorithm for an oral delivery. International Journal for Numerical Methods in Biomedical Engineering, 32(6), e02746. doi:10.1002/cnm.2746

Kannan, R., Przekwas, A. J., Singh, N., Delvadia, R., Tian, G., \& Walenga, R. (2017). Pharmaceutical aerosols deposition patterns from a Dry Powder Inhaler: Euler Lagrangian prediction and validation. Medical Engineering and Physics, 42, 35-47. doi:10.1016/j

Kannan, R., Singh, N., \& Przekwas, A. (2018). A compartment - quasi-3D multiscale approach for drug absorption, transport, and retention in the human lungs. International Journal for Numerical Methods in Biomedical Engineering, 34(5), e2955. doi:10.1002/cnm.2955

Klim, S., Mortensen, S. B., Kristensen, N. R., Overgaard, R. V., \& Madsen, H. (2009). Population stochastic modelling (psm)-an r package for mixed-effects models based on stochastic differential equations. Computer methods and programs in biomedicine, 94(3), 279-289.

Kramer, W. G., Lewis, R. P., Cobb, T. C., Forester, W. F., Visconti, J. A., Wanke, L. A., ... Reuning, R. H. (1974). Pharmacokinetics of digoxin: comparison of a two and a three compartment model in Man. Journal of Pharmacokinetics and Biopharmaceutics, 2(4), 299-312.

Kwon, Y. (2001). Handbook of essential pharmacokinetics, pharmacodynamics, and drug metabolism for industrial scientists. New York: Kluwer Academic/Plenum.

Reuning, R. H., Sams, R. A., \& Notari, R. E. (1973). Role of pharmacokinetics in drug dosage adjustment. I. Pharmacologic effect kinetics and apparent volume of distribution of digoxin. The Journal of Clinical Pharmacology, 13, 127-141.

Vallner, J. J., Stewart, J. T., Kotzan, J. A., Kirsten, E. B., \& Honigberg, I. L. (1981). Pharmacokinetics and bioavailability of hydromorphone following intravenous and oral administration to human subjects. The Journal of Clinical Pharmacology, 21, 152-156.

Widder, D. V. (1966). The Laplace Transform. Princeton University Press. 